\title{
A PRELIMINARY SOCIOLINGUISTIC SURVEY OF NUBRI VALLEY*
}

\section{Cathryn Donohue}

This paper reports results of a preliminary sociolinguistic survey that was carried out in Nubri Valley. Interviews were taken with people from throughout the valley. Some of the main findings are described here. The Nubri-perceived differences in dialect intelligibility and social status are discussed as well as the overall language vitality in the context of evolving social practices and observed language shift in the younger generations.

Keywords: language practices, language attitudes, sociolinguistic survey, language vitality, Nubri

\section{Nubri valley}

Nubri Valley is situated in northern-central Nepal in upper Gorkha district of Gandaki zone in Nepal. Said to have been settled by Tibetans some four hundred years ago (Childs 2004), this beyul, or 'hidden valley' is home to the Nubripa, or Nubri people. Most Nubris speak the Nubri language (iso 639-3 kte), though in the Kutang area, Kuke is spoken, and in the more recently settled Samdo village in the north-west, the villagers speak a language almost certain to be a dialect of Kyirong Tibetan. While Tibetan remains the liturgical language and the language of traditional festivals, younger generations are increasingly using Nepali, even between themselves, as more are going to Kathmandu for schooling where Nepali is the medium of instruction and of the playground. As the national language Nepali carries prestige, but it is also the language of the screen and contemporary songs, and a language symbolic of economic opportunity and modernity. Further, government teachers and health assistants assigned to the area typically do not speak Nubri, resulting in widening domains of potential language attrition.

There are approximately 2000 people across Nubri Valley (Simons \& Fenig 2018), with roughly 800 located in Samagaun (or Sama village), the largest of the Nubri. ${ }^{1}$ There are

* This work would not have been possible without the help of Nyima Samdup who helped administer some of reportedly 500 monolingual speakers of Nubri in the valley, though it is unclear how many of the 2000 speak primarily Nubri, nor is it clear how different the varieties of Nubri are. Ethnologue reports four main dialects (Sama, Lho, Namrung and Prok), though it is universally accepted in Nubri valley that the dialect spoken in Samagaun is the most distinct from other varieties, which my fieldwork has confirmed. With the exception of a couple of short word lists, and a recently published lexicon (Dhakal 2018), Nubri remains largely undescribed and undocumented. However, growing interest in the variety has resulted in more recent studies, including a detailed account of case marking (Donohue 2018, Donohue 2019) and tone (C.Donohue \& M.Donohue 2019; M.Donohue \& C.Donohue 2019), and the grammatical use of tone (Donohue 2020).

The data presented here are the result of a preliminary survey carried out in Nubri valley in May 2018, sampling 33 speakers.

\section{Survey methodology}

The survey consisted of a printed two-page (fourcolumn) sheet of questions for the speakers. The surveys were undertaken in Nubri Valley, in Nubri language. The participants were asked a range of questions about the language that fell under a few main categories which I outline below. Some of the questions were inspired by a previous survey of Manang (Hildebrandt et al. 2015; Hildebrant \& Hu 2017).

The first section asked about their personal details to see how they identified in terms of linguistic proficiency and the extent of travel out of the

the surveys. I would also like to express my gratitude to Research Services, the Faculty of Arts, and the Knowledge Exchange Office at the University of Hong Kong for grants that have supported this work including numerous field trips to Nepal. Thanks also to Mark Donohue for comments on an earlier draft.

${ }^{1}$ Thanks to Ula Jigme Tsewang of Samagaun (personal communication) for this estimate.

Nepalese Linguistics, vol. 34, 2019, pp. 10-17. 
valley as a possible influencing factor on their language choices. They were asked for theirclan identification, name/age/gender and their relative linguistic proficiencies with languages typically found in the area including Nubri, Nepali, Tibetan, English, Kuke and "other" (to be specified). They had to indicate their selfassessment on a five-point scale from 'fluent' to 'not at all'. It also sought information about where they live or have lived and for how long, and whether they travel out of the valley and if so, where they travelled to, for how long they went each time, and how often they travelled out of the valley.

The second part of the survey went into the family background to determine the exposure the participant had to different languages in the home and potentially to the influence of languages used in the parent's background or education that might have influenced the participant's language practices, especially during their formative years. They were asked what languages the parents and siblings spoke, the educational background of the parents and their occupations, what languages the participant spoke at home with parents/siblings/relatives.

The third part of the survey asked about their current home life to establish current linguistic influences: whether they were married, whether they had children, and the languages spoken at home now and as part of their daily life.

The fourth part of the survey enquired about their educational background, continuing to address the potential role of language contact: how many years of formal education, the medium of instruction, and where it took place, additionally addressing what their current occupation is and what languages are used at work and so forth.

The fifth part of the survey focused on linguistic variation and intelligibility to try to establish, from a Nubri perspective, how different the various dialects are from one another. The participants were given a list of key villages in Nubri Valley, and were asked to identify where they thought Nubri was spoken regularly, where people spoke exactly like them, where Nubri was spoken the 'most purely', where was the best place to learn Nubri, and in which villages did the locals speak differently to them. Additionally, they were asked to identify the degree to which they typically understood a speaker from each of the identified villages from a list of choices (a five-point scale, as with their own linguistic proficiencies).

The final section focused on issues of language vitality to get a sense of the attitudes towards the language. It consisted of a set of open-ended questions. The participants were asked if they felt Nubri was important to their culture, or to them personally, whether they thought children will keep learning Nubri, and whether that was important to them. Further they were asked to share what they thought could be done to encourage Nubri to be spoken by future generations, and finally what it means (to them) to be a Nubripa. The questionnaire is included as an appendix to this paper.

\section{Main results}

The survey responses were interesting, with a few key points standing out that I will identify below. In this paper I focus on the issues of mutual intelligibility and how the Nubripa negotiate their linguistic interactions.

As noted, Nubri Valley encompasses more than just the Nubri-speaking area: it includes Samdo in the northwest and Kuke-speaking villages in Kutang in the southeast.

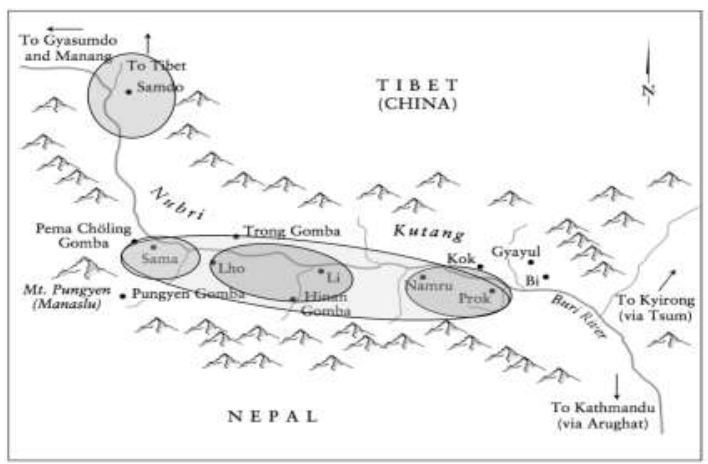

Figure 1. Location of identifiable dialect and language areas in Nubri Valley.

Figure 1 situates the varieties on a map, identifying Samdo in the northwest, three main dialect areas inside Nubri valley (Sama, Lho, Prok). The rest of Kutang in the south-east (of 
12 / A preliminary sociolinguistic...

which Nubri-speaking Prok is technically a part) speaks Kuke.

One result that is immediately apparent is the perception of relative prestige of the different Nubri varieties/languages depending on the home village/native variety of the participant.

As shown in Figure 2, Kuke is uniformly perceived as a low prestige language, both from within as well as without.

Tibetan, as the liturgical language, retains a high prestige status, while Nepali has a middling prestige. This may well change as the shift towards Nepali in the younger generation continues, and not just as a growing tendency to be schooled in Kathmandu. For many people, Kathmandu has become a year-round residence for the promise of greater socio-economic opportunities.

Within the Nubri varieties, Sama dialect perceives itself as having high prestige, though this is not shared outside the village. The effect this has on negotiating linguistic interactions is discussed later.

Conversely, no other villages perceive their own varieties as having 'high prestige', but from outside villagers, Lho variety was perceived as the most prestigious. From within, both Prok and Lho villagers perceived their own varieties as having 'middle prestige', but from outside, Prok variety is thought of as low prestige. This sits with another asymmetry we will see later in Figure 4 and related discussions that Prok identifies with the Lho variety, but speakers from Lho claim that they do not speak exactly the same in Prok village. These results are summarized in Figure 2a and represented graphically in Figure $2 b$.

\begin{tabular}{|l|l|l|}
\hline Language & $\begin{array}{l}\text { Self- } \\
\text { perception }\end{array}$ & $\begin{array}{l}\text { Others' } \\
\text { perception }\end{array}$ \\
\hline \hline Samdo & Middle & Low \\
\hline Sama & High & Middle \\
\hline Lho & Middle & High \\
\hline Prok & Middle & Low \\
\hline Kuke & Low & Low \\
\hline Tibetan & & High \\
\hline Nepali & & Middle \\
\hline
\end{tabular}

Figure 2a. Perception of prestige of different varieties spoken in Nubri Valley.

This sense of prestige bears directly on the language choices made in linguistic interactions.

Everyone speaks Sama Nubri with people from Sama, and people from Sama speak Sama variety with Nubris across the valley. This unwillingness to accommodate fits with the sense of high prestige the Sama villagers have of their variety, and the knowledge from the outside that the Sama people are (consequently) not very proficient in other varieties.

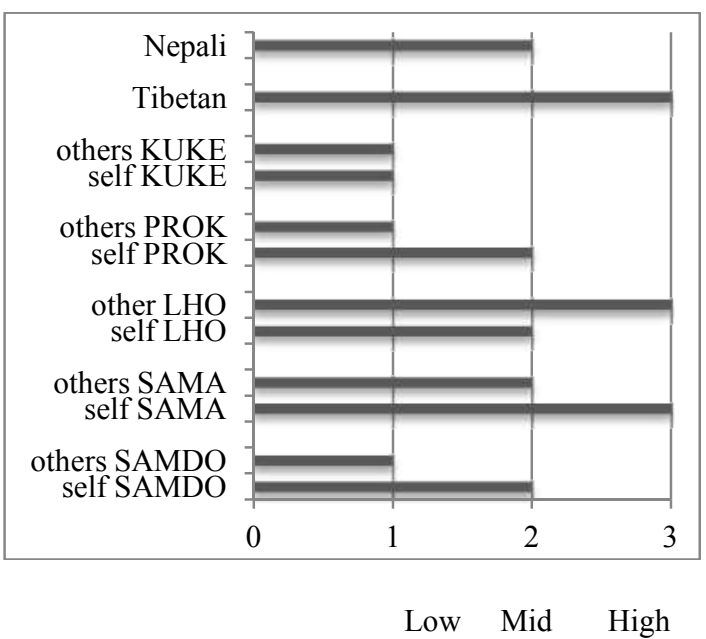

Figure 2b. Bar chart of local dialect perceived prestige in Nubri Valley.

The villagers from Samdo, aside from accommodating to Sama Nubri with nearby Sama villagers, will speak Tibetan outside their home village (or Nepali, if they can, further afield in lower Nubri/Kutang). Similarly, those from outside Samdo will use either Tibetan or Sama Nubri to talk to the Samdo villagers.

The Lho villagers will use Tibetan or Sama Nubri to talk to the Sama/Samdo villagers north of them, but Lho variety throughout the rest of the valley. This situation is reciprocated from others around the valley in interactions.

Prok villagers similarly speak Tibetan or Sama Nubri with Samdo/Sama villagers, Lho variety with those from Lho and Prok variety with their own villagers and in Kutang. This is also true of 
how others perceive their interactions with the Prok villagers.

The Kuke villages in Kutang will speak Tibetan with those from Samdo, and Prok Nubri throughout the rest of the Nubri speaking part of the valley, Kuke in the Kuke villages in Kutang. Other villages from outside the Kuke speaking area will speak their own variety of Nubri or Nepali with Kuke speakers.

\begin{tabular}{|l||l|l|l|l|l|}
\multicolumn{1}{||}{} & Samdo & Sama & Lho & Prok & Kuke \\
\hline \hline Samdo & Samdo & Sama & Tibetan & $\begin{array}{l}\text { Tibetan/ } \\
\text { Nepali }\end{array}$ & $\begin{array}{l}\text { Tibetan/ } \\
\text { Nepali }\end{array}$ \\
\hline Sama & Sama & Sama & $\begin{array}{l}\text { Sama/ } \\
\text { Tibetan }\end{array}$ & Sama & $\begin{array}{l}\text { Sama/ } \\
\text { Nepali }\end{array}$ \\
\hline Lho & $\begin{array}{l}\text { Tibetan/ } \\
\text { Sama } \\
\text { Tibetan/ }\end{array}$ & Sama & Lho & Lho & $\begin{array}{l}\text { Lho/ } \\
\text { Nepali }\end{array}$ \\
\hline Prok & Sama & Sama & Lrok & $\begin{array}{l}\text { Prok/ } \\
\text { Nepali }\end{array}$ \\
\hline Kuke & Tibetan & Prok & Prok & Prok & Kuke \\
\hline
\end{tabular}

Figure 3. Language of preferred communication

The data reported above from the survey is also reflected in the sense of perceived intelligibility of neighboring varieties of Nubri as shown in Figure 4.

\begin{tabular}{|c|c|c|c|c|}
\hline & \multicolumn{3}{|c|}{ Speaker } \\
\hline & & Sama & Lho & Prok \\
\hline \multirow{3}{*}{$\stackrel{\ddot{n}}{\vec{\Delta}}$} & Sama & $100 \%$ & $93 \%$ & $89 \%$ \\
\hline & Lho & $67 \%$ & $100 \%$ & $95 \%$ \\
\hline & Prok & $58 \%$ & $100 \%$ & $100 \%$ \\
\hline
\end{tabular}

Figure 4a. Reported intelligibility between Nubri varieties.

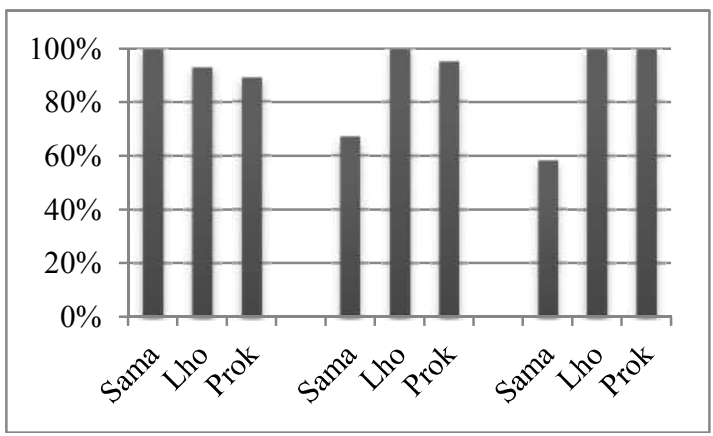

Figure $4 \mathrm{~b}$. Bar chart of reported intelligibility of main Nubri varieties (clustered along the x-axis) by speakers of these different villages indicated by the name of their home village at the top of each cluster).
The Lho villagers basically understand Prok Nubri, but only about two-thirds of what Sama Nubri speakers are saying. While all Nubris basically understand the Lho variety very well.

As noted the Sama variety is only understood about two-thirds of the time by Lho villagers, and even less by those from Prok. Indeed, at only a reported 58\% intelligibility rate for Prok villagers listening to Sama Nubri, it raises the question of whether they are indeed different dialects of different languages. The Sama people claim to understand Prok variety at a much higher rate. However, it is important to recall that the Sama villagers typically chose to interact with other Nubris from around the valley in Sama dialect, so it is perhaps not surprising that they have a greater sense of intelligibility, or that the results appear one-sided, because the communicative situations are one-sided.

These results are somewhat consistent with the reported lexical similarities for the different varieties, as shown in Figure 5 (Webster 1992). It is clear that Prok variety is more different from Sama Nubri than Lho variety, but 25 years later, it seems that Prok and Lho varieties are more similar to each other now, than either is to Sama variety. With Sama's strong sense of identity it is perhaps not surprising that they may be evolving differently to the rest of Nubri varieties. It is also perhaps not surprising that Prok variety is becoming more similar to that spoken in Lho, with which they claim identity (though those in Lho still find a difference).

\begin{tabular}{|c|c|c|c|}
\hline & Sama & Lho & Prok \\
\hline Sama & $100 \%$ & & \\
\hline Lho & $93 \%$ & $100 \%$ & \\
\hline Prok & $78 \%$ & $79 \%$ & $100 \%$ \\
\hline
\end{tabular}

Figure 5. Lexical similarities between Nubri varieties (Webster 1992).

\section{Discussion}

In summary, we see that Samdo is not merely a dialect of Nubri, but rather a separate language. This is not surprising, as it is a relatively recent arrival to the valley $(\sim 1961)$ and is more closely related to nearby Kyirong Tibetan. 
14 / A preliminary sociolinguistic...

Within Nubri there appear to be three main dialects:

Samagaun, as the largest village, has the greatest self-perceived sense of prestige. Although this perception of prestigeis not shared throughout the valley, it does impact how they choose to negotiate communications through a relative lack of accommodation.

Lho variety appears to approximate a 'standard' dialect for Nubri being the most readily understood variety by Nubris from throughout the valley. Lho dialect is uniformly seen as a good place for learning 'pure' Nubri. This may be due to an attitude towards the variety, but it may also be due to the fact that there is the big Ripum monastery in Lho, so the notion of purity may be due to the relatively large number of monks living there.

Prok speakers think of their own variety as being roughly the same as the variety spoken in Lho. However, it is quitedifferent as seen through the relative intelligibility (especially as perceived from without) and lexical similarities. Its differences are most likely due to its location in Kutang surrounded by Kuke speaking villages and the inevitable language contact.

\section{Concluding remarks}

This paper is the first report of a valley-wide survey. Although only a preliminary study it establishes the broad strokes of the linguistic landscape in Nubri Valley, previously only hinted at in the context of dialectal comparisons of specific topics (e.g. case marking, see Donohue 2018, 2019).

It establishes that there are three main dialects, and discusses how these varieties are different and, crucially, how they are evolving.

The Nubri identity is complex: ethnically Tibetan, politically Nepalese, they look to Kathmandu as a centre for socio-economic opportunities. More and more children go to Kathmandu for schooling, forgoing Tibetan schools of Dharamsala in India and other purely Tibetan options.

With these evolving socio-cultural practices come changing linguistic practices. Nubri is seen as the language of tradition, a tradition represented by the poor subsistence farming lifestyle with little or no connection to modernity or potential for prosperity. Perhaps through the influx of technology through smart phones, the somewhat disgruntled youth are looking for greater opportunities outside the valley that further threatens the vitality of the language. Already 'definitely endangered' according to UNESCO definitions (UNESCO 2003), the current practices suggest the need for language maintenance work, with a focus on boosting its usage in the younger population. Indeed, the future of the language lies with this demographic. To this end, I recently carried out discussion about orthographic possibilities with a range of speakers of all ages from around the valley and hope to be able to introduce a community-endorsed writing system soon.

Sample survey to follow as appendix

\section{References}

Childs, Geoff. 2004. Tibetan diary: From birth to death and beyond in a Himalayan Valley of Nepal. Berkeley: University of California Press.

Dhakal, Dubi Nanda. 2018. A Nubri Lexicon. Munich: Lincom Europa

Donohue, Cathryn. 2018. Case marking in Nubri. Nepalese Linguistics 33: 28-33.

Donohue Cathryn. 2019. Differential object marking in Nubri. Under review.

Donohue, Cathryn. 2020. Tonal morphology in Sama Nubri: Case marking and valency alternations. To appear in Studies in Language.

Donohue, Cathryn, and Mark Donohue. 2019. The complexity of tone in Nubri. To appear in Nepalese Linguistics 34 (this volume).

Donohue, Mark, and Cathryn Donohue. 2019. The vowels of Nubri from the perspective of other Tibetan languages. Under review.

Hildebrandt, Kristine, Dubi Nanda Dhakal, Oliver Bond, Matthew Vallejo, and Andrea Fyffe. 2015. A Sociolinguistic Survey of the Languages of Manang, Nepal: Co-Existence and Endangerment. National Foundation for Development of Indigenous Nationalities Journal14.6: 104-122.

Hildebrandt, Kristine, and Shunfu Hu. 2017. Areal analysis of language attitudes and 
practices: A case study from Nepal. Language documentation and conservation. Special Publication 13: 152-179.

Simons, Gary F. and Charles D. Fennig (eds). 2018. Languages of the world, $21^{\text {st }}$ edition. Dallas, TX: SIL International. Online version http://www.ethnologue.com

UNESCO Ad Hoc Expert Group on Endangered Languages. 2003. Language vitality and endangerment. Prepared for: International expert meeting on the UNESCO Programme Safeguarding of Endangered Languages, Paris. Accessed online at https://unesdoc.unesco.org/ark:/48223/pf000018 3699 on 25 July 2019.

Webster, Jeff. 1992. A sociolinguistic survey of the Tibeto-Burman dialects of North Gorkha District, Nepal. Kathmandu, SIL; MS. 
Nubri Language Survey・May 2018 (NS)

Location:

Date:

Thank you for participating in this study about Nubri language. Your name will not appear in the study unless you want to be identified.

Do you agree to be recorded, or video-ed? Yes/No Do you want to be identified in the study? Yes/No

Do you agree to have the recordings made available:

- In an academic setting only? Yes/No

- Publically available? (including online) Yes/No

\section{A. General information}

1. What is your name?

2. With which clan do you identify?

3. How old are you?

4. What is your mother tongue?

5. What languages can you speak:

Nubri:

$\square$ fluently $\square$ very well $\square$ somewhat $\square$ not much $\square$ not at all

Nepali:

$\square$ fluently $\square$ very well $\square$ somewhat $\square$ not much $\square$ not at all Tibetan:

$\square$ fluently $\square$ very well $\square$ somewhat $\square$ not much $\square$ not at all English:

$\square$ fluently $\square$ very well $\square$ somewhat $\square$ not much $\square$ not at all Kuke:

$\square$ fluently $\square$ very well $\square$ somewhat $\square$ not much $\square$ not at al Gurung:

$\square$ fluently $\square$ very well $\square$ somewhat $\square$ not much $\square$ not at all Ghale:

$\square$ fluently $\square$ very well $\square$ somewhat $\square$ not much $\square$ not at all

Other:

$\square$ fluently $\square$ very well $\square$ somewhat $\square$ not much $\square$ not at all

What languages do you speak in normal daily life?

Nubri: $\square$ Always $\square$ a lot $\square$ somewhat $\square$ a little $\square$ never

Nepali: $\square$ always $\square$ a lot $\square$ somewhat $\square$ a little $\square$ never Tibetan: $\square$ Always $\square$ a lot $\square$ somewhat $\square$ a little $\square$ never English: $\square$ always $\square$ a lot $\square$ somewhat $\square$ a little $\square$ never Other: $\quad \square$ Always $\square$ a lot $\square$ somewhat $\square$ a little

6. Where were you born and how long did you live there?

7. How often do you travel outside your village?

8. Where do you typically go, for what purpose?
Cathryn Donohue, HKU Linguistics

9. Which months do you usually travel in?

10. Do you use Facebook or messaging apps? Y/N 11. What language(s) do you use in this context? Nubri:

$\square$ Always $\square$ a lot $\square$ somewhat $\square$ a little $\square$ never Nepali:

$\square$ always $\square$ a lot $\square$ somewhat $\square$ a little $\square$ never

Tibetan:

$\square$ Always $\square$ a lot $\square$ somewhat $\square$ a little $\square$ never

English:

$\square$ always $\square$ a lot $\square$ somewhat $\square$ a little $\square$ never

Other:

$\square$ Always $\square$ a lot $\square$ somewhat $\square$ a little $\square$ never

\section{B. Family background}

1. Are your parents living now?

$\mathbf{Y} / \mathbf{N}$

Mother/Female parent:

What village was your mother from?

What is her mother tongue?

What languages does/did she speak:

Nubri

$\square$ fluently $\square$ very well $\square$ somewhat $\square$ not much $\square$ not at all

Nepali

$\square$ fluently $\square$ very well $\square$ somewhat $\square$ not much $\square$ not at all Tibetan

$\square$ fluently $\square$ very well $\square$ somewhat $\square$ not much $\square$ not at all English

$\square$ fluently $\square$ very well $\square$ somewhat $\square$ not much $\square$ not at all Other?

$\square$ fluently $\square$ very well $\square$ somewhat $\square$ not much $\square$ not at all

How much education did she have?

What does/did she do?

Father/Male parent:

What village was your father from?

What is his mother tongue?

What languages does/did your father speak:

Nubri

$\square$ fluently $\square$ very well $\square$ somewhat $\square$ not much $\square$ not at all Nepali

$\square$ fluently $\square$ very well $\square$ somewhat $\square$ not much $\square$ not at all Tibetan

$\square$ fluently $\square$ very well $\square$ somewhat $\square$ not much $\square$ not at all English

$\square$ fluently $\square$ very well $\square$ somewhat $\square$ not much $\square$ not at all Other?

$\square$ fluently $\square$ very well $\square$ somewhat $\square$ not much $\square$ not at all

How much education did he have? 
What does/did he do?

Do you have any siblings? Are you the eldest, youngest or in the middle?

When you were a child, what language(s) did you speak with your siblings? (Always?/ a lot?/ sometimes?)

When you were a child, what language(s) did you speak with your friends? (Always?/ a lot?/ sometimes?)

\section{Current situation}

1. Are you married?

2. Do you have any children?

3. Who lives at home with you?

4. What language(s) do you mostly speak with your spouse?

With your children?

5. What language(s) do you speak with your friends?

\section{Work and education}

1. Did you have formal education as a child? $\mathbf{Y} / \mathbf{N}$

3. In what language?

4. Did you use any other language(s) at school? $\mathrm{N} / \mathrm{Y}$ :

5. How many years (what levels) of formal education did you receive?

6. Where did you study?

7. What is your current occupation?

8. What languages do you use at work?

\section{E. Variation and intelligibility}

In which Nubri village(s) is Nubri spoken regularly? $\square$ Samdo $\square$ Sama $\square$ Lho $\square$ Li $\square$ Namrung $\square$ Prok $\square$ Other:

In which Nubri village(s) do people speak exactly like you?

$\square$ Samdo $\square$ Sama $\square$ Lho $\square$ Li $\square$ Namrung $\square$ Prok $\square$ Other:
In your opinion, in which village(s) in Nubri is spoken most purely?

In which Nubri village(s) do people speak a little differently from you?

$\square$ Samdo $\square$ Sama $\square$ Lho $\square$ Li $\square$ Namrung $\square$ Prok

$\square$ Other:

If someone wants to learn Nubri which is the best village for them to go to?

How well do you understand someone speaking Nubri from:

Prok $\square$ always $\square$ a lot $\square$ somewhat $\square$ a little $\square$ never

Namrung $\square$ always $\square$ a lot $\square$ somewhat $\square$ a little $\square$ never

Li $\quad \square$ always $\square$ a lot $\square$ somewhat $\square$ a little $\square$ never

Lho $\quad \square$ always $\square$ a lot $\square$ somewhat $\square$ a little $\square$ never

Sama $\square$ always $\square$ a lot $\square$ somewhat $\square$ a little $\square$ never

Samdo $\square$ always $\square$ a lot $\square$ somewhat $\square$ a little $\square$ never

Kutang $\square$ always $\square$ a lot $\square$ somewhat $\square$ a little $\square$ never

Other suggested village(s): $\square$ always $\square$ a lot $\square$ somewhat $\square$ a little $\square$ never

\section{F. Language vitality: (ideally recorded as well} as a summarized response)

1. Is your mother tongue important to your culture?

2. Is keeping your mother tongue important to you?

3. Do you think children will keep learning Nubri?

4. Should children be forced to learn Nubri? $\quad \mathrm{Y} / \mathrm{N}$

5. Is it important to you that children continue to speak Nubri?

6. What could be done to encourage Nubri to continue to be spoken by future generations?

7. What does it mean to you to be a Nubripa? 